\title{
LOS DISCURSOS SOBRE EL TRABAJO INFANTIL EN LA BARCELONA DEL SIGLO XVIII: CONSENSOS Y DISCREPANCIAS
}

\author{
Martín ItURRALde VALLS \\ Universitat de Barcelona
}

\begin{abstract}
RESUMEN. Aunque la mecanización y las nuevas fuentes de energía asociadas a la Revolución Industrial evidenciaron, más que nunca, el «problema» del trabajo infantil fabril, también en la Barcelona preindustrial existió una honda preocupación respecto al rol laboral de los niños en cuanto principal agente moralizador de la infancia de los pobres. Básicamente, los discursos y las preocupaciones giraban en torno al lugar, es decir, dónde debían trabajar los menores, hecho derivado del temor que infundía entre las élites la imagen de una infancia "descarriada» inmersa en la promiscuidad social de las nuevas industrias emergentes, como las indianas, alejadas del control gremial. Para llevar a cabo este estudio he recurrido a un amplio abanico de testimonios que abordan la problemática del trabajo infantil en la Barcelona del siglo XVIII, desde los círculos ilustrados a la Iglesia, pasando por las nuevas organizaciones industriales de los sectores emergentes y las instituciones de la ciudad.
\end{abstract}

Palabras clave: trabajo infantil, Antiguo Régimen, indianas, Barcelona, discursos.

\begin{abstract}
Although the mechanization and the new sources of energy associated with the Industrial Revolution evidenced, more than ever, the "problem» of factory child labor, there was also, in the pre-industrial Barcelona, a deep concern regarding the role of child work as the main moralizing agent of the childhood of the poor. Basically, the speeches and concerns revolved around the place, that is, where the children had to work, a fact derived from the fear that infused among the elites the image of a "wayward» childhood immersed in the social promiscuity of the new emerging industries, like the calico factories, away from the guild control. In order to carry out this study I have used a wide range of testimonies that address the problem of child labor
\end{abstract}

Recibido: 13-12-2018 • Aceptado: 25-2-2019·martin.iturralde@ub.edu 
in the Barcelona of the eighteenth-century, from enlightened circles to the Church, through the new industrial organizations of emerging sectors and institutions of the city.

Keywords: child labor, Ancien Régime, calico factories, Barcelona, discourses.

LAS INTERPRETACIONES en torno a los cambios discursivos sobre el trabajo infantil entre el Antiguo Régimen y el liberalismo distan, aun hoy, de estar cerradas ${ }^{1}$. En líneas generales, podría afirmarse que existen dos grandes líneas interpretativas que están estrechamente relacionadas con un hecho material concreto: la Revolución Industrial, especialmente la mecanización, y sus efectos sobre el trabajo infantil. La primera, considerada pesimista, sostiene que la industrialización tuvo efectos dramáticos en el trabajo infantil nunca antes vistos (Hammond, Thompson y Hobsbawm). Así, por ejemplo, parecería ser que en Inglaterra la Revolución Industrial incrementó el número de niños obreros procedentes de los sectores más depauperados (Humphries, 2010, p. 176), hecho que motivó la estigmatización de sus padres al ser considerados por parte de la patronal y otros círculos reformistas diversos como «egoístas» o vagos.

Sin embargo, otros investigadores, considerados optimistas, sostienen que la Revolución Industrial actuó como una «fuente de liberación» para los niños, cuyo trabajo, ya en el Antiguo Régimen, había sido masivo y realizado en condiciones de fuerte explotación. En otras palabras, la mayor competitividad del mercado de trabajo en la nueva sociedad industrial redujo las posibilidades de explotación de los menores (Nardinelli, 1990, p. 102). Asimismo, se ha sugerido que los cambios reales que acarreó la industrialización en Inglaterra fueron, en realidad, de menor calado que los denunciados hasta ahora por el discurso dominante de los pesimistas. De hecho, en fechas tan tardías como los años 50 del siglo XIX, en la siempre paradigmática Inglaterra era más frecuente encontrar niños trabajando en sectores tradicionales que no en las modernas industrias emergentes como el algodón (Kirby, 2009, p. 544). Desde esta perspectiva, ni siquiera el impacto del factory system en la salud de los menores habría sido tal, ya que su gran morbilidad, más que una consecuencia directa del trabajo fabril fue el resultado del ambiente generalmente insalubre de las grandes ciudades (Kirby, 2013, p. 46).

En cualquier caso, a lo largo de los últimos tres siglos de la historia contemporánea europea se han producido cambios discursivos que afectan a nuestra visión de la infancia y del trabajo infantil. Según la tesis ampliamente cuestionada de Ariès, la

Agradezco a la Dra. Cristina Borderías y a los evaluadores anónimos de este trabajo sus sugerencias, pues contribuyeron a mejorar su calidad. 
infancia, tal como la conocemos hoy en día, habría sido inexistente en la edad media (Ariès, 1987, p. 10), o, como señalan algunos de sus seguidores, una historia de progreso donde, cuanto más retrocedemos en el pasado, mayor insensibilidad había hacia los niños (Demause, 1982, p. 15). Aspectos como la inocencia, la individualidad o una mayor segregación del niño respecto al mundo de los adultos pasaron a conformar la nueva noción de la infancia contemporánea, lo mismo que una serie de nuevos derechos y privilegios, como, por ejemplo, el derecho de los niños a ser criados dentro de las familias y a tener una «infancia adecuada» (Cunningham, 2005, p. 203). No como en tiempos pasados donde muchos fueron obligados a abandonar prematuramente sus hogares para ganarse la vida fuera (Ferraro, 2012, p. 65).

Aunque también existen voces que sostienen que la relación entre padres e hijos siempre se basó, más allá de las convenciones morales de cada época, en la atención y los cuidados (Pollock, 1990, p. 309; Classen, 2005, p. 47; Ferraro, 2012, pp. 66-67; Stearns, 2017, p. 11; Grant, 2013, p. 105), parecería ser que el mayor de los cambios discursivos tuvo que ver con el distinto valor económico atribuido a los niños (Cunningham, 1994, p. 195). El tránsito de las sociedades de economía rural a las industrializadas conllevó cambios profundos, como la escolarización masiva de los niños, modificando así los propósitos de la infancia (Stearns, 2017, p. 9). Si en los siglos XVII, XVIII y XIX, ésta había sido vista como un tiempo de iniciación en los hábitos de trabajo, a comienzos del siglo XX los menores de todas las clases comenzaron a ser vistos más «como un gasto que un provecho económico». Como es sabido, se trató de un cambio producido a raíz de las comparaciones entre las duras condiciones de los esclavos africanos y las de los niños trabajadores ingleses, conocidos popularmente como los blanquinegros (Cunningham, 1994, p. 81).

En nuestro país, algunos estudios han criticado que las tesis de Ariès convirtieron en esencia las formas contemporáneas de entender la infancia, además de ignorar las duras condiciones materiales de vida de los niños. Al igual que en Inglaterra, el cambio en el valor económico de los niños españoles ha sido considerado el principal viraje discursivo, de modo que la infancia habría sido reinterpretada como una «etapa débil que hay que proteger, que tiene necesidad de tutela, un campo de intervención y una inversión de futuro» (Santos Sacristán, 2002, p. 2). En nuestro país, la percepción de que el trabajo infantil fabril era un «problema» más que una «solución» (el trabajo rural siguió siendo considerado un «sano deporte» hasta hace relativamente poco tiempo), tuvo un prolongado período de gestación iniciado con las denuncias de higienistas y economistas sociales en los años treinta del siglo XIX. Concretamente, a causa de la amenaza que suponía para el trabajo adulto la competencia de los niños gracias a la mecanización de algunas fases de la producción. Una percepción que, como sabemos, también hicieron suya los círculos obreros en las primeras décadas 
del siglo XX, una vez identificados los efectos negativos que el trabajo infantil tenía en el trabajo masculino adulto (Borrás, 2013, pp. 409-450).

Aunque mucho menos conocidos, en el mundo preindustrial el trabajo infantil también suscitó conflictos que generaron nuevos discursos no siempre coincidentes. Sin embargo, rápidamente fueron eclipsados en el imaginario colectivo a causa del potencial dramático de la imagen, tantas veces evocada con tintes dramáticos, de los niños «blanquinegros» atados a las máquinas de las modernas y humeantes fábricas de vapor del XIX.

Precisamente, este artículo analiza los principales discursos sobre la infancia y el trabajo infantil en la crisis del Antiguo Régimen en Barcelona. El objetivo es saber de qué manera y por qué el secular consenso en torno al trabajo infantil, asumido por los reformistas ilustrados a lo largo de la mayor parte del setecientos como una «solución», comenzó a sufrir a finales del XVIII los primeros embates mucho antes de la generalización de la nueva maquinaria y las nuevas fuentes de energía, que a partir del XIX estarían fuertemente relacionadas con la explotación de los menores.

Concretamente, nos centraremos en las indianas o telas de algodón estampadas, un sector manufacturero libre de ordenanzas gremiales que llegaría a convertirse en el principal motor económico de Barcelona en el siglo XVIII, ciudad que acogió la mayor concentración de protofábricas dedicadas a esta industria emergente en toda Europa. Asimismo, la llegada de dicho sector, considerado la primera fase de la futura industria moderna algodonera, anticipó problemáticas en torno al trabajo infantil que posteriormente, ya en el XIX, serían tratadas por los seguidores de las ideologías obreras, higienistas, reformistas y demás tendencias de una manera mucho más profusa.

Para la realización de este artículo hemos contado, en primer lugar, con las obras de algunos de los pensadores más influyentes de los distintos ámbitos económico, político, científico y religioso del período en cuestión. Así, empezando por el ideario ilustrado, he analizado parte de la obra de Lorenzo de Hervás y Panduro (1735-1809), concretamente su Historia de la vida del Hombre. Tomo 1: concepción, nacimiento, infancia y niñez del Hombre, (1789). Su importancia radica, precisamente, en haber sido uno de los mayores conocedores de la infancia de su época. También he recurrido a la obra de Antoni de Capmany (1742-1813), cuyas ideas sobre el aprendizaje y el trabajo infantil se encuentran recogidas en el Discurso económico-político en defensa del trabajo mecánico de los menestrales y de la influencia de sus gremios en las costumbres populares, conservación de las artes y honra de los artesanos, (1778) y en las Memorias históricas sobre la marina, comercio y artes de la antigua ciudad de Barcelona, (1779-1792). Su importancia consiste en haber sido uno de los principales defensores del sistema de aprendizaje gremial en un contexto convulso donde estaban surgiendo sectores emergentes no gremiales como las indianas. No menos importante, 
también desde la apología de los gremios, es la visión del jurista y economista Francesc Romà y Rossell (1725-1784), contenida en su Disertación histórico-político-legal por los colegios, y gremios de la ciudad de Barcelona, y sus privativas, (1766).

Por lo que respecta a las instituciones, he analizado la variada documentación oficial - edictos, informes, ordenanzas, correspondencia varia, etc.- generada por los siguientes organismos: el Ayuntamiento, la Junta de Comercio, la Real Compañía de Hilados de Algodón y el Cuerpo de Fabricantes. Todo ello sin olvidar el Obispado de Barcelona, la Junta de Sanidad, la Casa de Misericordia y el Hospital de la Santa Creu. Dicha documentación se halla repartida entre la Biblioteca de Catalunya, el Arxiu Diocesà de Barcelona, el Arxiu Històric de la Ciutat de Barcelona y el Arxiu Històric de la Fundació Casa de Misericòrdia de Barcelona.

\section{Contexto general y principales líneas del pensamiento económico}

Hasta la finalización de la Guerra de Independencia, la población barcelonesa se movió dentro de los cauces de lo que podría denominarse una sociedad «tradicional» (Romero, 2005, p. 38). El entramado social de la ciudad correspondía aún a una sociedad estamental formada por la nobleza local, la burguesía mercantil y unas clases trabajadoras formadas principalmente por artesanos. La progresiva mecanización del algodón habría propiciado que, por primera vez, estas clases populares se dividieran entre aquéllos cuya situación dependía de la nueva industria y aquéllos que aún vivían de las viejas actividades preindustriales (Romero, 2005, p. 38). Pero los inicios de la proletarización entre la población trabajadora barcelonesa apuntaron ya a raíz de la implantación de las fábricas de indianas, desde el segundo tercio del siglo XVIII (Mora, 2011, p. 238). Una industria que a finales de dicho siglo era ya la primera de la ciudad. Las tres fábricas existentes en el año 1738 se habían convertido en 22 en el año 1768 y en 84 en el año 1791, mientras que el número de trabajadores pasaba de 300 en 1738 a 2500 en 1768 y a cerca de 12.000 en 1791. Uno de cada seis trabajadores en la década de los ochenta en Barcelona trabajaba ya en la indianería, es decir, fuera de los gremios (Sánchez, 2011, p. 10).

La explosión de la nueva industria y la transformación de las estructuras gremiales a finales del siglo XVIII trajeron consigo, la creciente competencia entre los hombres - agremiados - y las mujeres - excluidas de los gremios - y las quejas y las denuncias constantes de los primeros por intrusismo y las presiones para expulsar a las mujeres de las manufacturas. La penetración a finales del siglo XVIII de las nuevas relaciones de producción capitalistas en las artes tradicionales y el incremento de la competitividad, favorecieron la exclusión de las mujeres de los gremios y la posterior expansión del trabajo femenino no regulado como método para reducir los 
costes de producción (Romero, 2005, p. 58). Los fabricantes de indianas recurrieron también a la explotación intensiva del trabajo infantil, siguiendo los principios de la concentración de la mano de obra, la división sexual y generacional del trabajo y la aplicación de una rígida disciplina fabril.

Los efectos del trabajo infantil en la indianería no fueron juzgados por todo el mundo de igual manera. Su magnitud e importancia amenazaban con liquidar definitivamente el antiguo consenso - roto inicialmente por Campomanes - en torno al aprendizaje gremial como vía de iniciación laboral de los niños. Esta nueva realidad, cada vez más evidente, generaría algunos debates no solo económicos, sino también morales y políticos que contarían con la participación de algunos de los pensadores y las instituciones barcelonesas más importantes, ya fuera a favor o en contra de las nuevas posibilidades que ofrecía a los niños esta nueva modalidad de trabajo extragremial. Cabe preguntarse, por tanto, si a pesar de estas diferencias podría hablarse de la existencia de un discurso hegemónico sobre el trabajo infantil en el siglo XVIII o, en su defecto, qué tipo de conflictividad habría existido entre los distintos discursos, sus puntos en común, sus diferencias y cómo se resolvieron estas tensiones.

Los economistas preclásicos europeos, como Bernard de Mandeville, defendían el aumento de la población para acrecentar la producción nacional (Gallego, 2010, p. 15). Entre los mercantilistas ingleses, la meta de exportar mucho con precios competitivos en términos absolutos les llevaba a argumentar a favor de los salarios bajos $\mathrm{y}$, en consecuencia, de una abundante mano de obra que favorecería el abaratamiento del factor (Gallego, 2010, pp. 27-28). En la España de Carlos III, el reformismo ilustrado encabezado por Pedro Rodríguez de Campomanes también consideraba el aumento de la oferta de trabajo como un objetivo prioritario del gobierno (Sarasua, 2004, pp. 171-191). La propuesta de Campomanes, concretada en el modelo de industria popular o dispersa, exigía la inclusión de los niños entre los miembros activos de la economía del país. El aspecto moral del trabajo y la condena de la vagancia -incluida la de los niños - tendrían un peso decisivo en el discurso poblacionista de Campomanes, supeditado a traducir el tan ansiado incremento demográfico en un aumento efectivo de la población trabajadora, es decir, «más súbditos sí, pero más súbditos útiles, no mendigos» (Sarasua, 2004, pp. 171-191).

El discurso de Campomanes sobre el trabajo infantil no era muy distinto del que había entre los ilustrados en Cataluña. Aquí, el mercantilismo en su versión cameralista había sido la doctrina económica de mayor arraigo entre los ilustrados catalanes del siglo XVIII, quienes compartían con Campomanes el mismo entusiasmo por el trabajo infantil fundamentado en las tesis poblacionistas. En Cataluña: «l'industrialisme i el poblacionisme van ser característiques típiques del mercantilisme que complementaren el desig d'una balança comercial favorable», ya que si: 
S'afavoria el creixement de la població, aquesta produiria més, i es podia vendre més a qui tenia els diners. D'aquesta manera, de l'interès pel comerç exterior es va passar a fomentar la població, i de la riquesa com a acumulació de metalls a la producció, i especialment de productes de luxe, ja que qui tenia els diners eren els compradors d'aquests productes (Argemí d'Abadal 2005, p. 57).

En definitiva, la actitud poblacionista de los mercantilistas catalanes se sustentaba sobre tres pilares fundamentales: generar un mayor volumen de población productiva, y también población como base de la imposición y del ejército $\mathrm{Y}$ es en este contexto político y económico donde hemos de situar el significado concreto del trabajo infantil a finales del siglo XVIII.

Si las necesidades del Estado eran las que explicaban desde un punto de vista económico las causas del trabajo infantil, el discurso ilustrado también ofrecía razones de carácter filosófico para justificar el empleo de los niños en las tareas productivas: la búsqueda de la felicidad. En este sentido, los tres ilustrados, cuya obra analizaremos a continuación compartían la visión de que los niños, cuanto antes comenzaran a trabajar, antes ocuparían «sin disgusto y con pleno convencimiento» su lugar en el entramado social. Un hecho que equivalía, según el ideario ilustrado, a ser felices y, de paso, a mantener el orden social. Para ello, analizaremos con más detalle cómo el discurso ilustrado en Cataluña daba respuesta a las siguientes cuatro cuestiones: a) ¿cuál era el concepto de infancia?; b) ¿desde qué edad y por qué los niños debían iniciarse en el trabajo?; c) ¿qué niños debían trabajar y en función de qué criterios se dividía el trabajo?; d) ¿dónde debían trabajar los niños?

\section{La infancia de los ilustrados: antesala de la razón, y del trabajo}

En la Francia prerrevolucionaria, el filósofo Jean-Jacques Rousseau trazó en su Emilio las líneas maestras de lo que sería el modelo de la infancia contemporánea: una etapa plenamente diferenciada y con unas necesidades muy distintas de las de la vida adulta. Niños y niñas debían recibir enseñanzas distintas: mientras que aquéllos eran educados para ejercer la ciudadanía, las niñas lo eran para convertirse en buenas esposas y mejores madres.

En la Inglaterra del año 1748, el médico William Cadogan publicaría su obra titulada An Essay upon Nursing and the Management of Children from their Birth to Three Years of Age, donde exponía, avanzándose a Rousseau, las nuevas ideas sobre la singularidad de la infancia y la importancia de ofrecer a los niños unos cuidados específicos acordes a sus propias necesidades (Alysa-Levene, 2006, p. 12). La idea medieval del niño, como un simple homúnculo, parecía tener los días contados en diversas partes de Europa. 
La huella de éstos y otros pensadores europeos también se dejaría ver en España, principalmente, en la monumental obra del jesuita expulso Lorenzo de Hervás y Panduro que, como Rousseau, también consideraba que niños y niñas debían recibir enseñanzas distintas. No obstante, Hervás sostiene que, además de aprender «sus» labores, las niñas debían ampliar sus conocimientos y recibir algunas nociones de religión, civilidad e instrucción científica, todo ello por un motivo muy concreto: su papel fundamental, en cuanto futuras madres, como primeras educadoras de sus hijos. Varones y hembras debían recibir esta educación diferenciada no a cualquier edad, sino en la niñez propiamente dicha: «pasa el hombre desde su infancia (que ocupa el primer septenio de su vida) al estado que llamamos niñez. Ésta en los varones dura otro septenio y solamente cinco en las hembras» (Hervás y Panduro, 1789, tomo 1, p. 316). La diferencia principal entre la infancia y la niñez era el uso o no de la razón: si la infancia era la etapa irracional de la vida, la niñez era la fase en que aparecían la conciencia y la capacidad de razonar y, por tanto, el momento idóneo de iniciar los respectivos aprendizajes. Un hecho que tendría profundas implicaciones en la iniciación laboral de los menores y en la división sexual del trabajo, como podremos ver a lo largo de este estudio.

Otro de los aspectos centrales que nos recuerda la influencia de Rousseau, pero sobre todo de Cadogan, es la nueva sensibilidad mostrada por algunos ilustrados españoles hacia la infancia y los cuidados específicos que ésta exigía. Dado que los infantes no gozarían de una existencia plena, feliz y verdadera hasta que se vieran dotados de razón, Hervás sostenía que éstos eran seres incompletos que, debido a su irracionalidad, había que proteger y cuidar, aplicando para ello los principios fundamentales de la razón ilustrada. No reclamaba únicamente la participación de los súbditos en el cuidado de los infelices infantes, sino también de las autoridades públicas (Hervás y Panduro, 1789, tomo 1, p. 190). Si cuidar de la infancia — atendiendo a sus necesidades específicas - era necesario en términos religiosos y humanitarios, también lo era en términos económicos: reducir la mortalidad infantil equivalía a aumentar la oferta de trabajo, aspecto central de las tesis poblacionistas cuyo objetivo era potenciar el Estado. Meta que, dicho sea de paso, compartían Capmany, Romà y Rossell y, desde luego, también Campomanes.

Pero ni la infancia ni su vulnerabilidad duraban para siempre. La fragilidad de la infancia, según Hervás, se atenuaba a medida que los pequeños, más o menos a los siete años, desarrollaban la capacidad de razonar, hecho que daba paso a la niñez y a la asunción de un mayor número de responsabilidades. Y entre éstas, cabe destacar no sólo los preceptos religiosos que la Iglesia mandaba, sino también —en el caso de las élites - iniciar una educación formal y, para la mayoría de los niños y niñas, incorporarse al mundo laboral. 


\section{Trabajar es «razonable»: el trabajo de los niños y las necesidades del Estado}

Sin duda, existía cierto consenso en torno a esta idea de que fuesen los niños y las niñas de siete años en adelante los que debían incorporarse al trabajo, no antes. Así lo sugería no solo Hervás, sino también Campomanes, quien descartaba como posibles trabajadoras a las niñas «que aún no han llegado a la edad de siete años» (Campomanes, 1774, p. 47); la Iglesia, que consideraba como posibles trabajadores infantiles a todos aquellos menores que tuviesen entre siete y quince años» $»^{2} \mathrm{y}$, en general, las instituciones ilustradas de la época, que clasificaban como «inútiles» a los niños «que no llegaban a los siete años de edad» y como «semiinhábiles» a los niños «de siete a doce años, cuya clase puede aplicarse a un mediano trabajo proporcionado a sus fuerzas y talento» ${ }^{3}$. En este caso, el discurso viene a confirmar que no era un hecho común, ni socialmente aceptado, el que los menores por debajo de los siete años fuesen ofrecidos por sus padres para conseguir un empleo. Si la infancia era el tiempo de recibir unos cuidados, por mínimos que fueran, la niñez era el momento de empezar a trabajar.

A diferencia de lo que ocurriría después con los higienistas de mediados del siglo XIX, los ilustrados en la Cataluña del setecientos no prestaban tanta atención a la situación doméstica y/o particular de las familias para ahondar en las causas del trabajo infantil. El que los niños trabajaran no era un problema, sino una solución, y las reflexiones de los ilustrados — apuntando casi siempre hacia instancias más elevadassolían centrarse en las necesidades del Estado - y no en las de las familias - para analizar las causas del trabajo infantil. Éste era, antes que un asunto de incumbencia doméstica, un asunto político y una pieza más del gran proyecto poblacionista que debía vigorizar al Estado.

Esto no quiere decir que los ilustrados no se refirieran a veces a la importancia del trabajo infantil para la supervivencia del propio niño o para complementar las maltrechas economías familiares, pero eran las menos. Así, por citar algunos ejemplos, Lorenzo de Hervás y Panduro destacaba la importancia de aprender a hacer media, bordar y hacer encaje, para que «las [niñas] que por ser de nacimiento pobre, se ven obligadas a mantenerse con sus trabajos, encuentren muchos géneros de vivir» (Hervás y Panduro, 1789, tomo 1, p. 373). O que era la pésima situación económica de la «gente plebeya, porción mayor del estado, y la opresión miserable de las fami-

Archivo Diocesano de Barcelona (en adelante A.D.B), Estado de las fábricas de indianas de la presente ciudad, (1784), IV Communium.

Colección de las memorias premiadas y de las que se acordó se imprimiesen sobre los cuatro asuntos que por encargo particular publicó la Real Sociedad Económica de Amigos del País de esta Corte en el suplemento de la Gazeta de 14 de agosto de 1781, p. 5. 
lias pobres, cargadas de hijos, e incapaces de educarlos, [la causa que hacía] útiles sus trabajos pueriles» ${ }^{4}$. O la importancia que tenía el aprendizaje precoz de un oficio durante la infancia, respecto a lo cual Romà i Rossell señalaba el valor del aprendizaje para proporcionar a los niños los conocimientos técnicos necesarios para formar artesanos cualificados.

Pero, como decíamos, el trabajo infantil era un asunto de interés público y la retórica de los ilustrados seguía incidiendo en las necesidades del Estado para difundir dicho trabajo, como evitar los efectos nocivos de la ociosidad. Los niños, como señalaba Antoni de Capmany, debían esquivar la ociosidad cuanto antes. Tanto, que esperar a conocer su vocación profesional era una pérdida de tiempo que podía condenar al menor a ser un adulto inútil para sí mismo o, lo que es peor, para el resto de la sociedad (Capmany, 1778, p. 54). Un discurso muy parecido al de Romà, quien destacaba la importancia del trabajo infantil como herramienta de control social para evitar que los aprendices — por su juventud y/o procedencia humilde — se desentendieran de sus ocupaciones y se arruinaran a sí mismos, desperdiciando parte de la mano de obra disponible y aniquilando, en definitiva, el propio proyecto poblacionista (Romà i Rossell, 1766, pp. 20-21).

Para los ilustrados en Catalunya, como también para los del resto de España y Europa, la aplicación al trabajo de los niños era la única forma de preparar ciudadanos felices a largo plazo. Si la razón era la vía para conseguir la felicidad, el trabajo era el vehículo para llegar a ésta. Eso sí, entendiendo la felicidad como el hecho de que cada uno, en el complejo entramado de una sociedad estamental, aceptase «sin reparo ni disgusto alguno» el puesto que estaba destinado a ocupar: es decir, que el artesano fuera un buen artesano y no mirase «con horror el trabajo», sino con orgullo. Los hijos de los pobres, como señalaba Bernard de Mandeville, no debían recibir educación pública porque podría cambiar sus costumbres, haciéndoles perezosos o conduciéndoles a rechazar tareas que antes de mejorar su formación sí habrían aceptado (Gallego, 2010, p. 21). Sin duda, una actitud que convenía fomentar desde las etapas iniciales de la vida, cuando el niño aún no había tenido tiempo ni oportunidad de conocer otras realidades distintas de aquélla que le tocaría vivir. Es, desde esta perspectiva, que el trabajo de los niños, siempre que estuviesen dotados de razón, no significaba una crueldad para los ilustrados, sino la única forma de crear a largo plazo, y de forma plenamente consciente, adultos felices, es decir, conformes, satisfechos y que no cuestionasen el orden social establecido.

Diario de Barcelona, (1795), Archivo Histórico de la Ciudad de Barcelona (en adelante A.H.C.B.), 295H, Tomo 11, p. 1250. 


\section{El reparto de tareas en la Barcelona del siglo XVIII}

El principio de que «a cada grupo social le correspondiesen tareas distintas, era la base misma de la sociedad estamental» (Sarasúa, 2004, p. 8). Esta idea, fundamental en el discurso de Campomanes, era compartida por la totalidad de los pensadores ilustrados que estamos analizando. Según Hervás, la educación no era, ni debía ser, igual para todos. Muy pronto los caminos de los niños pobres y de los ricos divergirían inexorablemente: «los hijos de los artesanos, que solamente deben aprender un poco a leer, escribir y contar, se despedirán luego que den la lección; porque si se detienen muchas horas en la escuela, se acostumbran a la ociosidad, y miran con horror el trabajo» (Hervás y Panduro, 1789, tomo 1, p. 315).

La aplicación al trabajo de los niños de las clases subalternas partía de dos premisas básicas: son los miembros del pueblo los que deben trabajar y cuanto antes lo hagan, si es posible desde niños, mucho mejor. La definición de «pueblo» de Antoni de Capmany es consustancial a su misión en la sociedad: «el pueblo tiene el noble destino de dar la subsistencia a todas las demás [clases]», motivo por el cual conviene «separar este cuerpo primordial de la sociedad de todos los demás, a fin de que más dueño de sí, y libre de preocupaciones caballarescas pueda hacer a sus miembros útiles» (Capmany, 1778, pp. 1-2). Nuevamente el concepto ilustrado de utilidad, que junto al de felicidad deben guiar a las masas a ocupar con orgullo y pleno convencimiento su lugar en el entramado social: trabajar, sin disgusto ni frustraciones, actitud que redundaba en beneficio propio y en el del resto de la sociedad.

Pero como señala Sarasúa, «la diferencia fundamental entre los individuos, lo que determina de manera más directa el lugar a ocupar en la sociedad y en las leyes, la marca el ser hombres o mujeres» (Sarasúa, 2004, p. 9). Así, los ilustrados apoyaban la creación de una política económica basada en un mercado laboral dual, donde la mano de obra femenina fuese el «fundamento de la fuerza de trabajo industrial (y con menos status)» (Romero, 2010, p. 97). Hecho que explicaría las medidas caritativas y educativas dirigidas a las mujeres y las niñas, cuyo objetivo era, precisamente, relegarlas a un tipo de tareas muy concretas y favorecer la segmentación del mercado de trabajo. Por ejemplo, a través de las llamadas «escuelas fábricas», fundadas gracias a los privilegios que el Estado concedía a determinadas fábricas para que, bajo la cobertura de una supuesta formación, los fabricantes emplearan niños y niñas en sus talleres. $\mathrm{O}$ de las escuelas de hilar (o cobertizo), al servicio de las fábricas estatales (Romero, 2010, pp. 101-102).

Especializar a las niñas y las mujeres en determinadas manufacturas e industrias era un objetivo defendido no sólo por Campomanes, sino también por otros ilustrados como Romà y Rossell, quien abogaba por fijar una férrea división sexual del trabajo 
y fomentar, también, aquellas actividades que demandaran solamente mano de obra femenina (Romà i Rossell, 1768, pp. 177-178). Y no sólo para cumplir con los postulados poblacionistas, sino también, posiblemente, para evitar los conflictos derivados de la competencia entre los hombres, las mujeres y los niños por un mismo puesto de trabajo (Romà i Rossell, 1768, pp. 34-35).

Sin embargo, pese a que la idea de emplear a las mujeres y las niñas en la industria contase con un amplio eco en el discurso ilustrado, en la práctica no siempre era de esta manera. Así, en la principal industria de la ciudad, la indianería, nuestras evidencias muestran que se trató de un sector muy masculinizado, más, si cabe, entre los niños (Iturralde, 2014). En la indianería no hemos podido comprobar la existencia de «escuelas cobertizo» que sirvieran para explotar — a modo de ejército de reservaa las niñas en beneficio de las fábricas. Pero sí hemos encontrado otra modalidad de escuelas para niñas pobres que, por razón de género, difícilmente hallaban trabajo en las fábricas de indianas y que, quizás por ello, dichas escuelas — distintas a las «escuelas cobertizo»- podrían haberse convertido en una alternativa laboral para estas niñas. En otras palabras, ante la falta de perspectivas laborales para las niñas en la indianería, las autoridades ilustradas se esforzaban en buscarles otras salidas que combinaran formación y trabajo asalariado.

Sin duda, es un hecho de sobras conocido que en el setecientos las niñas, «aprendían a trabajar en las escuelas»; es decir, más que alfabetizarse, las menores eran instruidas en aquellas labores que luego de adultas podían servirles para ganarse la vida. Pero lo que no estaba tan claro hasta ahora, es que en la Barcelona del siglo XVIII las niñas, al margen de aprender sus labores en las escuelas, ganasen un dinero por ello, hecho que contribuía a su supervivencia. Las condiciones laborales de estas niñas barcelonesas están perfectamente explicadas en un documento aprobado por Real Orden de 2 de mayo de $1786^{5}$. Como veremos, la principal novedad de este documento es el establecimiento de un vínculo económico y laboral entre la maestra y la alumna. El problema fundamental era la acuciante falta de recursos económicos de las niñas, que ni podían dejar de trabajar por ir a la escuela ni contribuir en su mantenimiento «como en el día no hay fondos para la dotación de las maestras, y el vecindario del Quartel es generalmente el más pobre de la ciudad, para facilitar la asistencia a las escuelas se arreglarán maestras y discípulas al ajuste sobre la misma obra» ${ }^{6}$.

Asimismo, el tiempo invertido en el trabajo y los beneficios derivados de la producción debían repartirse entre la maestra y la alumna de la siguiente manera: «las

A.H.C.B., Reglamento para las escuelas de niñas de los ocho barrios del Quartel Quinto de la Ciudad de Barcelona, establecidas por don Francisco de Zamora, de la Real y Distinguida Orden de Carlos III, B $1786-8^{\circ}$ (op).

$6 \quad$ Ibidem. 
niñas han de trabajar en la escuela por el espacio de tiempo que ajusten con la maestra, a proporción de la dificultad de aprender la labor: y el precio de la hacienda que hagan en este tiempo se repartirá una parte a la niña y tres a la maestra» ${ }^{7}$. Incluso, como veremos a continuación, las propias autoridades asumen que el principal y verdadero estimulo de la niña - como en otras actividades remuneradas - es ganar dinero, más que aprender, algo mucho más relacionado con los intereses propios del mundo laboral que el educativo « si concluido el ajuste quiere continuar [la niña] todavía en la escuela, harán nuevo trato a proporción de la habilidad de la niña, y la calidad de la obra; pero siempre han de tener parte en el producto del trabajo la maestra y discípula, para que tengan estímulo mutuamente» ${ }^{8}$.

Sinceramente, no sabemos aún el grado de aplicación que tuvo esta propuesta de combinar trabajo asalariado y escolarización en Barcelona. De hecho, salvo algunas autoras la mayoría de estudios ni siquiera menciona el Reglamento (Venini i Redin, 1990-1991, pp. 63-70). Lo que sí sabemos es que en la Barcelona del siglo XVIII cuando algunos centros educativos hablaban de «enseñar», en realidad estaban demandando, de una forma más o menos encubierta, mano de obra infantil femenina asalariada. Al margen de las distintas modalidades utilizadas para educar y a la vez explotar el trabajo infantil, el discurso hegemónico de la época coincidía en la necesidad de hacer trabajar a todos los menores, niños y niñas, que fueran hábiles para el trabajo. Sin olvidar, eso sí, seguir una férrea división sexual desde edades muy tempranas.

Como vemos las discrepancias entre los ilustrados catalanes eran poco significativas en torno al trabajo infantil. El problema en la segunda mitad del siglo XVIII no radicaba ni en la edad de iniciación laboral ni en las causas de que los niños trabajasen. Tampoco en a quiénes les tocaba hacerlo o cómo debía repartirse el trabajo. El problema más importante respecto al trabajo infantil en la segunda mitad del setecientos sería, concretamente, dónde debían trabajar los niños. Y es a este asunto al que dedicaremos nuestra atención.

\section{El aprendizaje en los gremios}

Si el discurso ilustrado respecto al trabajo infantil comenzaba a mostrar ciertas grietas, era por los desencuentros surgidos en torno a la idoneidad o no del aprendizaje infantil en las corporaciones de oficio. Mientras Campomanes opinaba que los gremios eran los máximos responsables de la decadencia y el atraso de las artes en España, Capmany sostenía justamente lo contrario. Ilustrado pero dotado a la vez de una visión

Ibidem.

Ibidem. 
tradicionalista; Grau y López han destacado que Capmany «s'ha mantingut al llarg de tota la seva carrera fidel a l'idea d'una societat estamental en la qual l'alta cultura científica moderna, és el patrimoni de les clases privilegiades» (Grau y López, 1988, p. 20). Un hecho ligado, sin duda, a que «l'acceptació sincera i entusiasta del sistema de valors dels il.lustrats europeus no implica una crítica de la societat estamental i això, como hem vist, marca un limit de l'empresa il.lustrada de Capmany en el sentit de la difusió popular» (Grau y López, 1988, p. 29). Más diferencias: si Campomanes apostaba por una «industrialització a petit nivel, d'indústria rural lligada a les produccions pròpies del país», Capmany era partidario «d'un comerç fornit per un conjunt de gremis ciutadans, i centrat en les ciutats» (Abadal, 2005, p. 91). Sin embargo, lejos de confundir tradición con inmovilismo, era en ciertas particularidades de la historia de Catalunya - como las corporaciones de oficio - donde Capmany consideraba que reposaban las bases de la tan ansiada modernización del país. Como señalan Grau y López, para Capmnay, Catalunya era «un país abocat al progrés, aquesta singularitat deriba d'un sistema social que, tot separant el poble de les classes privilegiades, confereix unes gratificacions especials al treball manual» (Grau y López 1988, p. 33). Al margen de estas consideraciones históricas, Capmany defendía los gremios porque éstos «tot i encarir la producció, fan que no hi hagi atur i prevenen la crisi económica» (Abadal, 2005, p. 88). De hecho, la actitud de Capmany «es dirigeix als atacs que aquestes institucions rebien per part del mateix Campomanes» (Abadal, 2005, p. 88). Pero también se dirigía contra «els que reclamaben una llibertat absoluta, ja que aquesta tendiria a crear mals artesans i a empitjorar la producció del país» (Abadal, 2005, p. 88).

Resultaría difícil, sino imposible, desligar las reflexiones de Antoni de Capmany sobre el trabajo infantil de su apología de las corporaciones de oficio barcelonesas. Pero hemos de tener en cuenta que dichas reflexiones eran, en realidad, una visión idealizada de lo que debería ser el trabajo infantil, siempre en el contexto de los gremios tradicionales: si Capmany coincidía en algo con Campomanes, era en que ambos «tenien por d'una gran indústria: la que crea una massa de proletariat (problema polític important per a Campomanes) i d'actituds mercantilistes (recerca ferotge del benefici), rebaixadores de les virtuts de l'antic règim, per a Capmany» (Abadal, 2005, p. 91). Asimismo, para Capmany el trabajo infantil era el origen y/o medio de transmisión de uno de los rasgos definitorios que él mismo atribuía a los catalanes: la laboriosidad, fermento clave, como señalarían Grau y López, para conseguir la tan ansiada modernización del país. Y esta trasmisión debía hacerse en el marco de las corporaciones de oficio y no al margen de ellas, por los motivos que expondremos a continuación.

Aunque opuesta a la de Campomanes, la actitud de Capmany en defensa del trabajo infantil gremial no fue un hecho aislado entre los ilustrados catalanes. Así, 
también Romà i Rossell opinaba que los gremios reunían una serie de características que la nueva industria - lo mismo que el resto de sectores libres de ordenanzas gremiales - desposeía por completo. Principalmente, el estrecho vínculo entre el aprendiz y el maestro. Para Capmany, solo la férrea vigilancia del maestro podía sujetar y conducir al niño por la vía de la laboriosidad y la honradez, neutralizando el temperamento ocioso y vicioso propio de la niñez (Capmany, 1778, p. 25).

Además, para Capmany, el aprendizaje gremial ofrecía al menor la posibilidad no sólo de introducirse en un oficio y aprenderlo, sino también algo mucho más estimulante: un proyecto de vida a largo plazo, sustentado en el orgullo profesional y en el espíritu de superación y ejemplificado en la figura del maestro. Así, «una vez aprovechado para las artes un mozo indócil, o de perversas inclinaciones», cuando «entra a la clase de oficial... no le pueden faltar deseos de subir a la última clase... esta graduación engendra la emulación», motivo por el cual dicho autor consideraba que «el mancebo que aspira a la maestría, mucho antes ya muestra el porte y conducta del maestro y le aviva los deseos de salir de aquella clase» (Capmany, 1778, pp. 25-26). La atmósfera fuertemente corporativa de los gremios cobraba una especial relevancia desde un punto de vista pedagógico, dado que, al haber un colectivo de artesanos implicados en la resolución de problemas comunes, el niño:

Aprende a conocer mejor que el artesano solitario y errante sus propios intereses, y los de su arte en general. Unos hombres así constituidos, adquieren en sus dichos y acciones cierta madurez y circunspección: ya la frecuencia de tratar de la economía y policía de su comunidad les acostumbra a cierto orden en sus casas, donde la niñez de los aprendices tiene continuamente una escuela viva (Capmany, 1778, p. 24).

Estos beneficios derivados de la cultura del oficio entre los niños eran coherentes con los postulados mercantilistas de la época, focalizados, como decíamos, en el aprovechamiento de las fuerzas productivas del país, especialmente en las ciudades, centros de corrupción moral y ocio de la infancia «perdida» (Capmany, 1778, pp. 24-25).

Sin duda, el trabajo infantil gremial era la semilla de lo que Capmany consideraba una de las claves de la modernización del país, es decir, «la laboriositat catalana, perfectament sintonitzada amb l'esperit que anima les nacions avançadas» (Grau y López, 1988, p. 30). Pero mientras Capmany apenas se pronuncia sobre el trabajo infantil fuera de los gremios, Romà i Rossell sí, por ejemplo, en los hospicios. Bajo el argumento de que «no hay desorden del qual no pueda sacar alguna ventaja el buen gobierno», Romà i Rossell sugería utilizar como mano de obra a los miles de niños y niñas que, fruto del tropiezo, se hallaban lastimosamente inactivos en los hospicios españoles. Dicho autor se mostraba partidario de promover «por medio de una multitud de muchachos, que pueden ser conocidos, educados y empleados por el gobierno, 
lo más primoroso de las artes, la distinción y separación de clases, y otros puntos de importancia» (Romà i Rossell, 1768, pp. 36-37). Muy parecido, por tanto, a las ideas de Campomanes, quien declaraba que si en «los hospicios no se arregla la enseñanza y el trabajo, de manera que los hospicianos ganen para mantenerse [...] la policía del hospicio no ha llegado a su perfección» (Campomanes, 1784, p. 40).

Y no solo en los hospicios, sino también en algunas otras industrias al margen de los gremios que permitiesen acumular dinero — rasgo esencial y característico de las primeras fases de la doctrina mercantilista - y de aumentar la población activa con fines productivos e impositivos (Romà i Rossell, 1768, pp. 177-178).

Como vemos, al margen de las voces discordantes que había entre los propios ilustrados sobre la idoneidad o no del aprendizaje en los gremios, su discurso coincidía en muchos otros aspectos. Así, como hemos visto, respecto a la edad mínima de empezar a trabajar, las causas para hacerlo, qué sectores de la población debían iniciarse en el trabajo y la necesidad de dividir por sexos las tareas de los niños.

\section{Niños sin maestros: trabajo infantil y caos en las fábricas de indianas}

Este debate entre ilustrados sobre la idoneidad o no del aprendizaje gremial se vio, en parte, animado con la entrada en escena de los defensores a ultranza de las modernas fábricas de indianas — ni Campomanes ni Capmany lo eran, en esto sí coincidían - Los nuevos actores, la incipiente burguesía fabril, estaban representados por la Real Compañía de Hilados de Algodón y la Junta de Comercio de Barcelona. Dada la enorme trascendencia que tuvo la participación de los minyons en la indianería, las últimas décadas del siglo XVIII fueron escenario de las tensiones entre los defensores de la incipiente industrialización y los del tradicional sistema de aprendizaje gremial. Y aunque sus diferencias sobre el trabajo infantil parecían irreconciliables, lo cierto es que ambas posturas coincidían en un aspecto esencial: su interés en sacar el máximo beneficio posible de ese trabajo. El problema, más bien, era que los niños que debían trabajar no lo hicieran, o que, sobre todo, desde la perspectiva de los defensores de los gremios, los niños trabajasen en la nueva industria.

Ante la actitud hostil de los gremios, los partidarios de esa nueva industria no dudaban en mostrar sus credenciales exaltando los resultados beneficiosos, económicos y sociales, de la gran demanda de mano de obra joven en la indianería, pues ya:

Desde su introducción se ha aumentado una tercera parte la población del Principado y todos hallan en ella ocupación: habiéndose desterrado la holgazanería. Mas, por encontrar segura y útil ocupación los jóvenes y un medio seguro de ganarse el alimento para sí y su prole, es motivo de que contraen matrimonio en una edad competente, para lograr una sana y larga sucesión; no observándose aquel celibato 
forzado a que precisaba la falta de medios de sustentarse, cuando carecíamos de estas fábricas; por lo que la juventud del sexo fuerte solo encontraba el medio de desfogar sus pasiones en el destrozo de la humanidad 9 .

Como vemos, los defensores de la incipiente industrialización también echaban mano de la vieja ecuación poblacionista para justificar las virtudes del trabajo infantil, esta vez en sus modernas fábricas: tal como en su día hicieron Campomanes, Capmany, Romà i Rossell e incluso el propio Hervás.

Sin embargo, para los defensores de los gremios, las indianas constituían un desafío a sus intereses y al orden social establecido. Así, por ejemplo, el Barò de Maldà veía en el trabajo asalariado de las modernas fábricas de indianas una amenaza que debía ser erradicada cuanto antes. Como señala Pere Molas, «els treballadors de les fàbriques d'indianes, especialment els joves, apareixen més aviat als ulls del baró de Maldà com a elements negatius, pertorbadors de l'ordre social i moral, dins aquell concepte francès de «classes laborieuses, classes dangereuses», ben diferents dels menestrals agremiats» (Molas, 2002, p. 52). De forma muy explícita, el Barò de Maldà, denunciaba que «ab la mitat i encara ab la mitat de la mitat de fàbriques d'indianes nos en sobrarien, sent enfarfac tantes fàbriques per la corrupció de costums i males paraules en mossos, xicots i mossotes» (Amat i de Cortada, 1987, pp. 137-138).

A esto hay que sumar que no todos los minyons y los jóvenes eran vecinos conocidos de Barcelona, sino que, atraídos por las expectativas laborales en las fábricas, venían de otras poblaciones, hecho que aumentaba las sospechas hacia ellos:

Los mossos de les fabriques són de grave perjudici a les bones costums de molts i moltes d'aquí de Barcelona, pués bastant que s'experimenta la introducciò de les fabriques, per la malicia que cada dia més i més s'aumenta, i no sé en què vindrà a parar, des de que hi ha tanta xusma de tants mossos de fabriques i tantes nacions barrejades ab los catalans en aquesta ciutat, tan celebrada en altres temps per la candidès dels costums de sos moradors, i religió (Pascual Rodríguez, 2003, p. 74).

Los opositores al trabajo infantil en la nueva industria criticaban, sobre todo, la circulación de dinero fácil y la promiscuidad social imperante en las fábricas de indianas. En esta misma línea, la Real Audiencia denunciaba que:

Como no pide fuerza excesiva ni grande inteligencia el manejo de las indianas, todos se dedican a vivir en esta ligera ocupación que en pocas horas da un jornal excesivo, sin privar a los que le ganan de entretener sus vicios y ser unos miembros corrompidos y perjudiciales a la República. Los vagos tienen una fácil acogida y

Diario de Barcelona, (1797), A.H.C.B., Tomo 15, pp. 345, 346, 349, 350, 353, 354, 357, 358. 
por este medio se ocultan a los ojos de la justicia. Las costumbres se corrompen diariamente con la frecuencia de ambos sexos y se padecen graves menoscabos en lo más sublime de la Religión (Thomson, 1994, p. 280).

Para entender mejor este rechazo, hay que tener en cuenta que muy pocas cosas infundían mayor temor y respeto en una mente tradicional que la visión de una infancia desbocada. El niño, con inclinaciones perversas, no solo era un peligro hoy, sino una amenaza para el mañana. Quizás por esto, el culto al orden, la calculada puesta en escena y la exhibición pública de los niños de los gremios en las procesiones religiosas, eran una catarsis colectiva destinada a calmar las angustias y ansiedades que provocaba la infancia en proceso de degradación moral. Así, el Barón de Maldà narra, emocionado, la piadosa escena de una procesión en que:

La congregació del Sant Christo de la Aflicció incluía la presencia de fins a 14 noys vestis de vesta y atxa, y lo Sant Sepulcre sota talam anant quatre capellans de la parroquia al devant, y detrás tots los demes ab atxa, y alguns individus ab casacas, y demes negre, que cluhian la professo; la nota dels estaments de cada pas i misteri, y sos mayorals per quedar notats en lo diari de avui, nols repetesch en aquest llibre, si sols noto, que a cada noy dels vestits de vesta fins a 14, que serán fills dels butiguers, he sabut que sels regala a cada hú una capsa de confitura y un berenar ${ }^{10}$.

Sin embargo, los intentos de moralizar a los niños no se limitarían a las cofradías y a los gremios, sino que irían mucho más allá. Es decir, incluirían también a los miles de minyons empleados en las mismísimas fábricas de indianas. Vamos a ver a continuación cómo la Iglesia y la patronal trataron, no sin dificultades, de conciliar sus respectivos intereses: la propagación de la fe por un lado y la productividad y la maximización del beneficio por el otro.

\section{La «irrupción de la fe en las fábricas»}

Debido a la coincidencia de su episcopado en la diócesis de Barcelona con la fase de mayor expansión de la indianería en esta ciudad, fue gracias al obispo Gabino de Valladares y Mejía como hemos podido saber qué actitud tomó la Iglesia catalana ante la incipiente industrialización y la masiva contratación de niños que este proceso exigía. Antes de seguir cabe señalar un dato muy importante: si bien no existen pruebas, ni mucho menos, de que la Iglesia catalana se opusiera al trabajo infantil en la indianería, sí se puede detectar cierto grado de preocupación por las condiciones en que estos niños desarrollaban su trabajo. Conviene tener en cuenta que estamos

10 Baró de Maldà, Calaix de Sastre, (1793), A.H.C.B., Ms. A. 208, p. 191. 
en un momento en que al niño, para hacerlo virtuoso, había que aislarlo de cualquier tentación y, sobre todo, de las malas compañías. Algo que, desde luego, resultaba muy difícil de conseguir en las masificadas fábricas de la ciudad. Por eso, frente al rígido control social ejercido de forma secular en los talleres artesanos, donde los aprendices quedaban subordinados física y emocionalmente a la voluntad del maestro - recordemos, uno de los rasgos más valorados por Capmany — la fábrica se concebía negativamente como un espacio caracterizado por la promiscuidad social entre trabajadores de diferentes sexos y edades. La perniciosa convivencia bajo un mismo techo no sólo de hombres y mujeres, sino de cientos de niños que podían ser influidos negativamente por el ejemplo de los mayores, despertaba las sospechas de los líderes de la Iglesia. Sin embargo, éstos entendían que el trabajo infantil debía ser difundido igualmente. Eso sí, mejorando las condiciones espirituales en que se llevaba a cabo.

Seguramente por este motivo, Valladares mandó publicar en el año 1786 la que sería su carta pastoral de presentación o Prontuario de la Doctrina Cristiana (Bonet i Baltà, 1984, p. 93). Este catecismo, como señala Bonet i Baltà, cumplía dos objetivos muy importantes: adoctrinar y castellanizar a los miles de niños empleados en las fábricas. Pero como la mayoría de ellos sólo conocían su lengua nativa, el catalán, Valladares mandó editar una versión bilingüe «castellano-catalán» para que los menores entendieran el catecismo sin desobedecer por ello la «voluntat castellanitzadora de Carles III» (Bonet i Baltà, 1984, p. 96). Eran más de dos mil los minyons que trabajaban en las fábricas de indianas y pintados de la ciudad, cifra que representaba casi un 20 por ciento de la población infantil masculina de Barcelona a mediados de los ochenta. Seguramente, el colectivo profesional de niños más numeroso. Y así lo entendía Valladares, que establecía que «este objeto» — el adoctrinamiento y la moralización del trabajo infantil — iba particularmente dirigido al «mayor número de dichos niños [que] se compone de los que trabajan en las fábricas de lienzos pintados» (Valladares i Messia, 1786, s/p).

La Iglesia veía en el adoctrinamiento masivo de esta «plebe descontrolada de minyons» una nueva oportunidad para propagar su poder e influencia, inoculando en la juventud el «santo temor de Dios», e invitaba a los empresarios a colaborar «apelando a su cristianismo» y exponiéndoles las innumerables «ventajas que debe producirles el que manejen sus caudales unos hombres timoratos, instruidos en los principios de nuestra religión, y que sepan bien lo que manda y prohíbe en orden a sí, y a los próximos» (Valladares i Messia, 1786, s/p). Tal y como afirmaba Valladares, la moralización del trabajo infantil era, en términos globales, «el único medio (y creedme, hijos míos, que no hay otro) por donde, a más de formarse con el tiempo hombres justos y fieles para con Dios, se hacen hijos reverentes y obsequiosos para con sus padres, súbditos obedientes para con sus superiores, criados laboriosos y fieles para con los amos, y vecinos útiles a sus pueblos» (Valladares i Messia, 1786, s/p). 
Virtudes que parecían ser el remedio definitivo contra la indisciplina infantil y juvenil que los fabricantes y dueños hacía tiempo que venían denunciando enérgicamente ante la Real Compañía de Hilados de Algodón. Como es lógico, llevar a cabo esta campaña de adoctrinamiento masivo de los más de dos mil niños que trabajaban en las fábricas de indianas acarreaba una serie de dificultades que, por lo visto, Valladares no desconocía del todo. En primer lugar, la imposibilidad de encomendar la educación moral de cada niño a un hipotético maestro.

Si el Prontuario estaba dedicado a los minyons de las indianas era, precisamente, porque las autoridades eclesiásticas confiaban en que en el tradicional mundo de las corporaciones de oficio «son menos [los niños] empleados [y] se hace más fácil que los amos cuiden que se les enseñe» (Valladares i Messia 1786: s/p). Al menos en un primer momento, la solución parecía estar fuera de las fábricas. De modo que la Iglesia sugirió que los niños «que cada uno [de los amos] tiene empleados, vayan, en los días y horas que se publicarán separadamente, a oír la explicación de la doctrina a las parroquias e iglesias que se destinen por sus respectivos curas» (Valladares $\mathrm{i}$ Messia, 1786, s/p). Efectivamente, como sabemos a través de la documentación, la Iglesia trazó un minucioso plan para que los minyons de cada fábrica fuesen enviados a las parroquias en unos días y horas en concreto para iniciarse en el catecismo. Sin embargo, este plan de adoctrinamiento masivo exigía, un tanto ingenuamente, la colaboración e implicación personal de los dueños, como si fueran maestros, hasta el extremo de que «no dexen en estas ocasiones de acompañarles [a los niños] por sí, o por personas muy de su confianza, a fin de que no se extravíen en el camino [a la parroquia], estén oyendo la explicación con atención y quietud y se sepa después quienes faltan» (Valladares i Messia, 1786, s/p). Como veremos, el conflicto de intereses entre los empresarios y la Iglesia estaba servido. Seguramente, Valladares no fue del todo consciente de que moralizar a los minyons era un objetivo difícilmente compatible con la meta, plenamente capitalista, de los dueños: incrementar la productividad de la mano de obra infantil. Así, como muestra la nutrida correspondencia, mientras los dueños se mostraban flexibles y partidarios de tolerar cierta indisciplina con tal de no comprometer el ritmo de la producción con despidos masivos de niños, la Iglesia, «en su mundo», seguía empeñada justamente en lo contrario: castigar y forzar el despido de los minyons que no cumplieran con sus obligaciones religiosas.

Es decir, mientras los empresarios —más capitalistas que «buenos christianos»anteponían las necesidades de la producción a la disciplina, la Iglesia exigía lo opuesto: el castigo. Tanto, que Valladares conminaba a los dueños a vigilar «que se observe lo que se ha acordado en cuanto a que no admitan unos a los jóvenes que despidan otros, por no querer asistir a la doctrina en las parroquias» (Valladares i Messia, 1786, s/p). Se trataba, además, de impedir la propagación de la irreligiosidad entre los minyons, 
eliminando del sector a los irreverentes «amonestarles, y en su caso despedirles, porque no perviertan a los otros» (Valladares i Messia, 1786, s/p). Sin embargo, la paciencia de los empresarios se agotaría con la pretensión del obispo de adoctrinar a los niños no ya en las iglesias, sino en sus mismísimos puestos de trabajo, es decir, «irrumpiendo de lleno con la fe en las fábricas». Cegado por su afán moralizador, Valladares sostenía, entre otras muchas directrices, que «convendría mucho que en las fábricas se canten por los niños, alternando con alguno de los más despejados, que nombre el amo, aquellos puntos principales, cuya noticia es necesaria absolutamente a todo christiano [...] lo cual han de executar todos los días un rato por la mañana, y otro por la tarde, después de haber rezado de comunidad» (Valladares i Messia, 1786, s/p). Si como decíamos, los empresarios, más que «buenos christianos», eran capitalistas movidos por sus intereses económicos, las fábricas de indianas no eran — ni aspiraban a serlo de ninguna de las maneras - hospicios en donde el ritmo de la producción pudiese verse constantemente interrumpido para que los minyons recitaran el catecismo.

En síntesis, cabe señalar que la explotación intensiva de la mano de obra infantil exigía, entre otras cosas, un aprovechamiento minucioso del tiempo útil de trabajo, algo totalmente incompatible con las estrategias moralizadoras de Valladares. Asimismo, como hemos visto antes, en una fase expansiva del sector en la que toda la mano de obra infantil disponible parecía poca, los fabricantes no podían permitirse el lujo de castigar y/o despedir a todos y cada uno de los niños acusados de irreligiosidad por la Iglesia. Quizás, sean estas discrepancias las que expliquen por qué no hay en los archivos pruebas concluyentes que permitan confirmar el éxito de la campaña moralizadora de Valladares. Sin embargo, aunque la patronal y la Iglesia hablasen desde distintos ángulos, el discurso social imperante sobre el trabajo infantil —al que también coadyuvaron dichas instituciones - reconocía en la difusión de dicho trabajo un medio muy eficaz para alcanzar distintos objetivos, ya fueran religiosos, económicos o relativos al mantenimiento del orden social establecido.

\section{El trasfondo ideológico de un debate amable: la protomedicina y el empleo de los minyons en la indianería del setecientos}

La nueva problemática de los minyons de las fábricas de indianas no solo interesó a la Iglesia. Si el objetivo de ésta era actuar desde el plano espiritual, la protomedicina de finales del siglo XVIII, desde la Junta de Sanidad, se interesaría por las cuestiones fisiológicas del trabajo de los niños en las fábricas. Además, como veremos a continuación, la tendencia ilustrada -muy acusada en Capmany y en Romà i Rossell- de explicar el trabajo infantil desde la perspectiva y las necesidades del Estado se iría relajando, aunque no desaparecerá del todo por el momento. Es decir, aunque la evolu- 
ción será muy gradual, los discursos de estos primeros médicos sobre el trabajo infantil dejarán de ser estrictamente políticos - en la línea poblacionista de los ilustrados, esto es, los supuestos beneficios del trabajo infantil para el Estado - para ser cada vez más sociales - al centrarse en las ventajas y desventajas que dicho trabajo tendría directamente para los niños y sus familias - En este cambio, el papel de los médicos resultará fundamental. Los dictámenes, con resultados opuestos, de los médicos José Masdevall y Pedro Güell han sido analizados por los estudiosos de la indianería para estudiar el trasfondo del conflicto ocurrido tras la aprobación de dos edictos en 1784 que impedían, de modo temporal, el establecimiento de nuevas fábricas de indianas dentro de la ciudad. Los motivos aducidos eran, entre otros, los posibles efectos negativos que comportaba la indianería para la salud pública. Sin embargo, la prohibición de erigir nuevas fábricas ha sido considerada un simple episodio más dentro de la larga historia de desencuentros entre la Real Audiencia y la Junta de Comercio, organismos que no dudaron en blindar sus antagónicos puntos de vista sobre dicha medida amparándose en los citados dictámenes. Así, mientras que en el año 1781 el doctor Güell ya había elaborado un breve informe sobre las posibles consecuencias negativas que podían tener las fábricas de indianas para la salud, el doctor Masdevall contribuiría en el año 1784 a levantar la prohibición de erigir nuevas fábricas en Barcelona.

Aunque enfrentados entre ellos, ambos médicos reproducían —en parte- elementos del discurso social hegemónico sobre el trabajo infantil: que éste no era un problema al que hubiese que referirse como tal. Muy al contrario de lo que sucedería apenas medio siglo más tarde, cuando el trabajo infantil sí sería un asunto denunciado con fuerza por los primeros higienistas como Monlau, las autoridades sanitarias de finales del siglo XVIII no veían en el trabajo infantil un elemento negativo. Y no porque el trabajo infantil en la manufactura algodonera de finales del XVIII no fuera un hecho masivo, o porque las condiciones del trabajo infantil en este sector no fuesen lo suficientemente duras. Lo cierto es que - aunque sensible a las condiciones laborales de los trabajadores en general - el dictamen pesimista sobre las fábricas de indianas del doctor Güell ni siquiera mencionaba a los miles de minyons del pintador, pinseladors, minyons del prat o niñas devanadoras que trabajaban hasta catorce horas diarias en unas condiciones ciertamente insalubres. Omitiendo la suerte corrida por los niños, el doctor Güell y Pellicer afirmaba que:

Quantas veces se entra en las [fábricas] de indianas al asomarse a las salas de los texedores, de los pintores y de las mujeres que devanan, se experimenta cuasi en todas un tufo tan caliente y sofocante que obliga a compadecerse de la triste suerte de aquella ilustrísima parte del estado que en el mismo taller donde trabaja para ganar su vida destruye su vida con el ayre infecto que respira. Las más de aquellas piezas son en extremo pequeñas, bajas y poco aseadas. Particularmente en invierno, 
el número de gentes es mucho, y el calor y el trabajo aumentan su transpiración o sudor. La pelusa del algodón en unas salas y en otras las partículas de la pintura se esparcen por el ambiente; de todas estas causas resulta un aire caliente, poco elástico, denso y cargado de vapores animales, y exhalaciones nocivas que fatiga la respiración, relaja el cuerpo y le dispone a mil enfermedades crónicas y agudas que pueden muy fácilmente pasar a ser epidemias. Merece pues este punto la atención del gobierno para obligar a los dueños de las fábricas a que den más capacidad a sus talleres o pongan menos gente en ellos y que al mismo tiempo tengan su ventilador o a los menos muchas ventanas o respiradores que faciliten la circulación del aire exterior ${ }^{11}$.

Como vemos, la realidad de los miles de niños que trabajaban en el sector no sólo no se denunciaba, sino que pasaba absolutamente desapercibida. Por su parte, el doctor Masdevall sí se refiere a la situación de los miles de minyons que estaban empleados en las fábricas, pero adoptando un enfoque optimista que, sabemos, tenía como objetivo contribuir a levantar la prohibición de erigir nuevas fábricas en la ciudad. Así, en un ambiente en el que parecían mezclarse en partes iguales lo laboral con lo lúdico, Masdevall aseguraba haber visto que:

Los muchachos empleados en las referidas fábricas, por su genio travieso e inquieto, no solo se pintan las mexillas, párpados, boca y dientes con la masa compuesta de dixos ingredientes [...] sino que también algunas veces unos a otros se hacen tragar alguna porción de la referida masa, sin que haya la menor experiencia de que estas travesuras hayan ocasionado el menor daño a alguno de los mismos (Masdevall, 1797, p. 143).

Los vapores emanados de las calderas de avivaje producían, a su entender, efectos terapéuticos, tanto, que el propio Masdevall aseguraba haber entrado:

Varias veces en las referidas fábricas, he mirado muy de propósito el semblante y las facciones de aquellas gentes, que de todas edades se encuentran en ellas y a todas las he visto con buenos colores, con buen semblante, y en lo general mucho mejores y con un ayre mucho más fuerte y robusto que los demás habitantes de Barcelona (Masdevall, 1797, p. 152).

Si cincuenta años después Monlau expresaría su rechazo al trabajo infantil fabril aduciendo que se ponía en riesgo «el vigor físico que se adquiere en la infancia [...] fuerza de las generaciones adultas» (Monlau 1851, pp. 63-64), para Masdevall era todo lo contrario: el trabajo infantil vigorizaba al niño, convirtiéndole, incluso, en un adulto sano. Así, Masdevall sostenía que:

A.H.C.B., Junta de Comercio, 1L.IX-5, F, 11 de junio de 1781. 
En la villa de Olot son muchas las fábricas de estos tintes; conozco a muchos particulares que desde niños se han criado trabajando diariamente en las mismas, y los veo vivir sanos, robustos, contentos, ágiles y alegres [...] lo que manifiesta con la más clara evidencia, que si los que todos los días tienen sus cuerpos cubiertos de los humos y vapores que despiden las calderas de los tintes de las fábricas de lana, estás sanos, robustos, buenos, alegres, sin padecer el menor mal, no nos ha de quedar el menor motivo para creer que estas fábricas despidan hálitos y vapores que puedan ocasionarnos enfermedades (Masdevall, 1797, p. 151).

Desde la perspectiva de estos primeros médicos, el trabajo infantil estaba muy lejos de ser considerado una causa de mayor morbilidad. Antes, al contrario, Masdevall consideraba que el trabajo infantil era positivo, no ya para el Estado como solían reiterar insistentemente los ilustrados, sino para las propias familias, mejorando sus recursos y elevando sus niveles de vida, pues «estos hombres y los de menor edad, que están empleados en dichas fábricas, todos ganan un buen jornal, con cuyo motivo comen y beben bien, y están contentos y alegres. Este es uno de los poderosos medios para desterrar las enfermedades del cuerpo humano» (Masdevall, 1797, p. 152). Esta idea del trabajo infantil como fuente de bienestar puede verse también en las ventajas comparativas que ofrecía la industria rural a los niños y a las niñas de Cervera, frente a la falta de oportunidades y miseria que había en las zonas eminentemente agrícolas. Así, Masdevall secundaba las ideas de Campomanes sobre la industria rural, o los esfuerzos de la Real Compañía de Hilados por promover el hilado de algodón americano en los distintos pueblos de Catalunya:

Ha introducido y extendido mucho la hilanza del algodón entre los moradores de Cervera, como en otros parajes de aquel principado; en todas las puertas se ven gentes, niños y niñas que cantando y divirtiéndose están ocupados en dicha hilanza; gana cada uno de ellos un buen jornal, de modo que un padre que tiene tres o cuatro hijos o hijas de la edad de diez a diez y seis años tiene un patrimonio para pasarlo honestamente, pues que estos le ganan lo suficiente para mantenerse todos y comer pasablemente (Masdevall, 1797, p. 154).

\section{Conclusiones}

El largo proceso de decadencia y desaparición de las corporaciones de oficio en Barcelona y, junto a ellas, del sistema de aprendizaje gremial, no fue igual en todos los sectores. Mientras los gremios de tejedores de lana y los pelaires desaparecieron casi sin ofrecer resistencia, otros, como los carpinteros y cerrajeros se beneficiaron de la incipiente industrialización, llegando incluso a fundarse nuevos gremios en las primeras décadas del siglo XIX. 
En cualquier caso, para los detractores de los gremios y partidarios de la libertad de industria, el rígido sistema de aprendizaje de las corporaciones constituyó, hasta el final, un objeto de fuertes críticas. El aprendizaje representaba, prácticamente, la esencia del mundo gremial. Sin embargo, también era un medio clave, más allá de las cuestiones meramente técnicas, para la moralización de los trabajadores más jóvenes, entre los que había no solamente hijos de maestros relativamente bien acomodados, sino también menores huérfanos y abandonados cuya estigmatización y criminalización por parte de las elites no era infrecuente.

La asombrosa y nueva proliferación de decenas de fábricas de indianas, ajenas a los gremios y erigidas en el principal motor económico de la ciudad en el último tercio del XVIII, vino acompañada de un nuevo universo de significados en las relaciones laborales, tanto en las formas de contratación y remuneración como en la organización del trabajo y la disciplina. Pero también de la caída en desuso del tradicional vínculo personal «maestro-aprendiz», un mecanismo de control cuya ausencia encendió las alarmas ante la nueva «promiscuidad social» en la que debían «deambular» diariamente los miles de niños y niñas en los nuevos espacios fabriles, donde la convivencia entre sexos y edades, especialmente intensa, era un hecho preocupante para las elites ¿Se convertiría el trabajo, tradicional semillero de buenos hábitos para los hijos de los pobres, en un nuevo generador de delincuencia y corrupción moral?

A pesar de estos temores, el discurso social sobre el trabajo infantil en la Barcelona de fines del siglo XVIII todavía mostraba muy pocas discrepancias internas respecto a los temas de mayor calado. Ni la edad a la que los niños debían empezar a trabajar, ni a qué sectores sociales correspondía hacerlo, ni bajo qué criterios debía repartirse el trabajo, merecieron mayores objeciones en la época. Quizás, como resultado de la irrupción de las nuevas modalidades productivas derivadas de la incipiente industrialización, las primeras dudas respecto al trabajo infantil estuvieron relacionadas con el dónde debían trabajar los niños, es decir, las fábricas de indianas. Aunque estas dudas las podemos encontrar primero entre los propios ilustrados, concretamente entre Campomanes y Capmany, lo cierto es que la entrada en escena de los defensores de las nuevas fábricas, atrincherados en la Real Compañía de Hilados de Algodón, animaría más, si cabe, las discusiones sobre este asunto.

Pero en lo esencial, todos coincidían en lo mismo: la necesidad imperiosa de difundir el trabajo entre los niños de las clases subalternas para garantizar el funcionamiento armónico del cuerpo social. Además de satisfacer, dicho sea de paso, los intereses de las élites políticas, económicas y religiosas del país, los auténticos privilegiados del entramado social a finales del Antiguo Régimen. El trabajo infantil para los ilustrados era un asunto político y como tal debía ser analizado; esto es, colocando al Estado en el centro de sus reflexiones y, en un segundo plano, muy por detrás, a 


\section{MARTÍN \\ ITURRALDE VALLS}

los niños y a sus familias. Sin embargo, las nuevas ideologías desde el segundo tercio del siglo XIX — especialmente la economía social — ahondarían en la idea de que el «trabajo» ya no podía ser considerado indistintamente como el «remedio» frente a la desmoralización y la pobreza material, sino que podía convertirse, sobre todo en su vertiente fabril, en todo lo contrario.

\section{AGRADECIMIENTOS}

Esta investigación ha sido financiada por el proyecto: Mundos del trabajo en transición (1750-1930), Ministerio de Economía y Competitividad (HAR2017-84030P). 


\section{Bibliografía}

Amat I DE CORTADA, Rafael (1987), Calaix de Sastre, I, Barcelona, Institut Municipal d'Història-Curial Edicions Catalanes.

Argemi D'ABADAL, Lluis (2005), Història del pensament econòmic a Catalunya, Vic, Eumo.

Ariès, Philippe (1987), El niño y la vida familiar en el Antiguo Régimen, Madrid, Taurus.

Bonet i Baltà, Joan (1984), L’Esglesia catalana, de la Il.lustració a la Renaixença, Barcelona, Abadia de Montserrat.

Borras Llop, Jose María (2013), «Las organizaciones obreras y el trabajo infantil», en Borrás Llop, José María (ed.), El trabajo infantil en España (1700-1950), Barcelona, Icaria, pp. 409-450.

Capmany, Antoni de (1778), Discurso económico-político en defensa del trabajo mecánico de los menestrales y de la influencia de sus gremios en las costumbres populares, conservación de las artes y honra de los artesanos, Madrid, En la imprenta de Don Antonio de Sancha.

Classen, Albrecht (2005), «Philippe Ariès and the Consequences: History of Childhood, Family Relations, and Personal Emotions: Where do we stand Today?», en Classen, Albrecht (ed.), Childhood in the Middle Ages and the Renaissance: The Results of a Paradigm Shift in the History of Mentality, Berlin, Walter de Gruyter. https://doi.org/10.1515/9783110895445.1

Cunningham, Hugh (1994), Trabajo y explotación infantil. Situación en la Inglaterra de los siglos XVII al XX, Madrid, Ministerio de Trabajo y Seguridad Social.

Cunningham, Hugh (2005), Children and Childhood in Western Society Since 1500, Harlow, Pearson Longman.

Demause, Lloyd (1982), Historia de la infancia, Madrid, Alianza Editorial.

Ferraro, Joanne (2012), «Childhood in Medieval and Early Modern Times», en Fass, Paula (ed.), The Routledge History of Childhood in the Western World, London, Routledge.

Gallego, Elena (2010), Historia breve del mercado de trabajo, Madrid, Ecobook.

García BALAÑ̀̀, Albert (2002), La fabricació de la fàbrica. Treball i política a la Catalunya cotonera (1784-1884), Tesis doctoral, Universitat Pompeu Fabra.

Grant, Julia (2012), «Parent-child relations in Western Europe and North America, 1500-present», en Fass, Paula (ed.), The Routledge History of Childhood in the Western World, London, Routledge. 
Grau, Ramon y López Marina (1988), «Antoni de Capmany: el primer model del pensament polític català modern», en Albert Balcells (ed.), El pensament polític català: del segle XVIII a mitjan segle XX, Barcelona, Edicions 62.

Hervás y PANDURo, Lorenzo (1789), Historia de la vida del hombre, Tomo I, Concepción, nacimiento, infancia y niñez del hombre, Madrid, Imprenta de Aznar.

Heywood, Colin (2018), A History of Childhood, Cambridge, Polity Press.

Humphries, Jane (2010), Childhood and child labour in the British Industrial Revolution, Cambridge, Cambridge University Press. https://doi.org/10.1017/ CBO9780511780455

Humphries, Jane (2012), «Childhood and child labour in the British industrial revolution», The Economic History Review, 66, 2, pp. 395-418. https://doi. org/10.1111/j.1468-0289.2012.00651.x

KIRBY, Peter (2009), «History of Child Labor in Britain», en Hindman, Hugh (ed.), The World of Child Labor. An Historical and Regional Survey, New York, M. E. Sharpe. Inc, pp. 544-548.

KIrBY, Peter (2013), Child Workers and Industrial Health in Britain, 1780-1850, Woodbridge, The Boydell Press.

Levene, Alysa (2006), «Reasonable Creatures: A Common-Sense Guide to Childcare», History Today, 56, 12.

MASDEVAll, Jaume (1797), Relación de las epidemias de calenturas pútridas y malignas, que en estos últimos años sean padecido en Cataluña; y principalmente de la que se descubrió el año pasado de 1783 en la ciudad de Lérida, llano de Urgel, $y$ otros muchos corregimientos y partidos, con el método feliz, pronto y seguro de curar semejantes enfermedades, Madrid, En la Imprenta Real.

Molas, Pere (2002), «Reflexions sobre la societat barcelonesa del segle XVIII», Barcelona Quaderns d'Història, 7, pp. 51-69.

MorA, Natalia (2011), «El primer proletariat català. Mà d'obra i relacions laborals a les fàbriques d'indianes de Barcelona», en Sánchez, Alejandro (coord.), La indústria de les indianes a Barcelona, 1730-1850, Barcelona Quaderns d'Història, 17, pp. 237-252.

Moreno, Belén (2015), «El aprendiz de gremio en la Barcelona del siglo XVIII», Areas: Revista internacional de ciencias sociales, 34, pp. 63-75.

NARDinelLI, Clark (1990), Child labor and the industrial revolution, Indiana, Indiana University Press.

Pascual i Rodriguez, Vicenç (2003), El baró de Maldà. Materials per a una biografia, Publicacions de l'Abadia de Montserrat. Barcelona.

Pollock, Linda (1990), Los niños olvidados: relaciones entre padres e hijos de 1500 a 1900, México D.F, Fondo de Cultura Económica. 
Roma i Rossell, Francesc (1766), Disertación histórico-político-legal por los colegios, y gremios de la ciudad de Barcelona, y sus privativas, Madrid, En la imprenta de D. Antonio Muñoz del Valle.

Romero, Juanjo (2005), La construcción de la cultura del oficio durante la industrialización, Barcelona, 1814-1860, Barcelona, Icaria Editorial.

Romero, Juanjo (2010), «Estado, trabajadores y empleo femenino en los orígenes de la indústria en la España contemporánea», en del Val Valdivieso, María Isabel (coord.), El trabajo de las mujeres en España. Desde la Antigüedad al siglo XX, Dossier des Mélanges de la Casa de Velázquez. Nouvelle série, 40 (2), pp. 95-115. https://doi.org/10.4000/mcv.3593

SÁNCHEZ, Alejandro (2011), «Barcelona i la indústria de les indianes. Una presentació», en Sánchez, Alejandro (coord.), La indústria de les indianes a Barcelona, 17301850, Barcelona, Quaderns d'Història, 17, pp. 9-29.

SANTOS SACRISTÁN, Marta (2002), «Los malos tratos a la infancia: juristas reformadores y el debate sobre la patria potestad en el Código Civil español (1889-1936)», Cuadernos de Historia Contemporánea, 24, pp. 209-232.

SARASÚA, Carmen (2004), «Una política de empleo antes de la industrialización: paro, estructura de la ocupación y salarios en la obra de Campomanes», en Comín Comín, Francisco y Martín Aceña, Pablo (ed.), Campomanes y su obra económica, Madrid, Instituto de Estudios Fiscales, pp. 171-191.

Stearns, Peter (2017), Childhood in World History, New York, Routledge. https://doi. org/10.4324/9781315561363

Thomson, James (1994), Els orígens de la industrialització a Catalunya. El cotó a Barcelona, 1728-1832, Barcelona, Edicions 62.

Valladares i Mesia, Gabino (1786), Prontuario de la doctrina chrisitiana, que contiene los puntos más principales de ella. Se publica para el uso de los niños empleados en las fábricas de pintados de esta ciudad; y puede servir para que otros amos y padres enseñen por él a sus criados y familias. Por el Ilm. Sr Dn. Gavino Valladares y Mesía... Barcelona, por Francisco Surià y Burgada, Impresor de S. M. y de la Dignidad Epsicopal.

VENINI I REDIN, Elena (1990-1991), «El magisteri femení a Barcelona a les darreries del segle XVIII», Educació i cultura, revista mallorquina de pedagogía, 8 y 9 , pp. 63-70. 
